\title{
Research on the Structural Characteristics of Entertainment Industrial Correlation in China: Based on Dual Perspective of Input-Output and Network Analysis
}

\author{
Yang Xun $\mathbb{D}^{\mathrm{D}},{ }^{1}$ Wensheng Shi $\mathbb{D}^{2},{ }^{2}$ and Tianyu Liu $\mathbb{D}^{3}$ \\ ${ }^{1}$ School of Economics and Finance, Xi'an Jiaotong University, Xi'an 710049, China \\ ${ }^{2}$ Yulin University, Yulin 719000, China \\ ${ }^{3}$ School of Leisure Sport, Shanghai University of Sport, Shanghai 200444, China
}

Correspondence should be addressed to Wensheng Shi; 502420007@qq.com

Received 11 June 2021; Accepted 28 September 2021; Published 31 October 2021

Academic Editor: Fei Xiong

Copyright (c) 2021 Yang Xun et al. This is an open access article distributed under the Creative Commons Attribution License, which permits unrestricted use, distribution, and reproduction in any medium, provided the original work is properly cited.

Based on the dual perspective of input-output and network analysis, this study takes typical industrial sectors of China's entertainment industry as representatives. Through the input-output analysis of industrial correlation characteristic indicators and construction of an industrial correlation network, we conduct a systematic and quantitative study on the entertainment industrial correlation characteristics and structural characteristics of the industrial correlation network in China. Furthermore, we clarify the role of the entertainment industry in China's industrial development and its positioning in China's whole industrial correlation network. We have the following key findings: China's entertainment industry as a whole shows the characteristics of final demandoriented industries, whose rapid development plays a certain positive role in boosting consumption and driving economic growth. Within the whole industrial correlation network in China, there is frequent interaction between the entertainment industry and other industry sectors within the directly related network; it will especially exert obvious radiation and driving effect on the upstream industry. However, limited by the scale of the direct industrial correlation network, such influence is still difficult to achieve the common development of most industries in China.

\section{Research Background}

In recent years, with the rapid progress of productivity and economic and social undertakings, the overall income level of Chinese residents has been greatly improved, and entertainment and leisure have become increasingly important in people's daily life. As people's lifestyles show the characteristics of leisure and entertainment, more and more people are willing to devote energy, money, and time to participate in various forms of entertainment. Entertainment consumption has gradually become an important part of residents' daily consumption [1]. In this process, China's commercial entertainment industry has also ushered in a stage of rapid development. As a representative industry of the modern service industry, although China's entertainment industry started late, due to the acceleration of the domestic industrial structure transformation and upgrading and the rapid growth of entertainment consumption demand, the overall growth momentum of China's entertainment industry in recent years has been strong. Relevant statistics show that the scale of China's pan-entertainment core industry has maintained an average annual growth rate of more than 15\% from 2015 to 2019, which is significantly higher than the GDP growth rate during the same period [2]. It can be seen that the rapid development of the entertainment industry has gradually begun to play a role in boosting China's overall national economic growth.

Existing theoretical studies have shown that there is a natural direct connection between the production activities of the entertainment industry and various industries such as media, tourism, real estate, and catering. This connection will be further passed on to other industries through the 
exchange of intermediate products, which makes the entertainment industry show obvious industry linkage effects [3]. Therefore, a mature entertainment industry will have a greater radiation effect on the development of many industrial sectors in a country or region. At present, although China's entertainment industry has made considerable progress in the process of economic development in recent years, its extensive relevance with other industries and economic driving ability have also received general attention from the industry and academia, but existing researches show that the theoretical research on the economic effects of China's entertainment industry is still mostly at the qualitative level, and the positioning of the entertainment industry in the overall industrial structure of the national economy and the quantitative analysis of the characteristics of its industrial correlation structure are still relatively lacking [4]. Therefore, in order to deepen the understanding of the role of the entertainment industry in the development of China's industry and to further clarify the industry correlation and interaction effects between the entertainment industry and other industries, this study uses the latest input-output data released by the National Bureau of Statistics of China, combined with input-output analysis and network analysis to conduct a systematic and quantitative study on the characteristics of China's entertainment characteristics of industrial correlation and industrial correlation network structure, so as to provide theoretical support for further exerting the extensive driving role of the entertainment industry in the development of China's industry and accelerating the pace of industrial transformation and upgrading.

\section{Analytical Framework for the Characteristics of Industrial Correlation Structure of China's Entertainment Industry}

The traditional industry correlation analysis mainly uses the input-output table to reveal the interdependence between the sources of production input and the destination of output use among the various industrial sectors of the national economy. By converting the flow data in the inputoutput table into different coefficient matrices, various coefficients that reflect the direct and indirect economic links between industrial sectors can be calculated, so as to further carry out a more in-depth quantitative analysis of the relationship between industries [5]. However, although the classic input-output model can give a clear quantitative description of the relationship between the two industries, the information obtained through input-output analysis is too scattered, and it is difficult to fully reflect the positioning of the entertainment industry in China's complete industrial structure system and structural features. Therefore, if we want to systematically show the role of the entertainment industry in China's overall industrial layout, we need to find a basis from the perspective of network analysis.

As a new quantitative analysis method, network analysis integrates theories and research methods of statistics, topology, system dynamics, and other disciplines. By abstracting each action subject and their interrelationships in a complex network system into nodes and ties, network analysis can more comprehensively describe the whole structural characteristics of the network and the relationship between the subjects in the network [6]. At present, the research methods of network analysis have been widely used in most practical network research fields such as sociology, economics, and communication [7-9], especially in the field of industrial economics. The analysis of the industrial correlation network based on the input-output relationship has basically formed a relatively mature research framework, which provides new research tools for revealing the characteristics of the interconnected network between industrial sectors and grasping the direction of macroindustrial structure optimization. In the current related research on industrial correlation networks, the main research idea is to abstract each industrial sector as a node in network analysis and use the $0-1$ adjacency matrix formed by filtering various coefficients in the input-output model as the directed edge basis to build an industrial correlation network and quantitatively analyze the overall structural characteristics and node characteristics of the industrial correlation network such as network density, clustering coefficient, symmetry, and centrality degree, to systematically study the positioning of each industry sector and the characteristics of the overall industrial correlation structure in the industrial correlation network [10].

\section{Analytical Framework for the Characteristics of Industrial Correlation of the Entertainment Industry Based on Input- Output Analysis}

In the input-output analysis stage, this study will use the input-output table to calculate the direct consumption coefficient, direct demand coefficient, intermediate consumption rate, intermediate demand rate, diffusion coefficient, and inducing coefficient of China's entertainment industry. Through the analysis of the above-mentioned characteristic indicators, the research will clarify the quantitative relationship between the input and output of the typical entertainment industry sector from production to final use and other industry sectors and provide an overall analysis of the industry type and characteristics of China's entertainment industry. The analysis of the role played in the national economic system provides a basis for quantitative research on the structural characteristics of the industry's correlation network. The calculation methods and descriptions of specific characteristic indicators are as follows.

3.1. Direct Consumption Coefficient and Direct Distribution Coefficient. In the input-output analysis, the direct consumption coefficient refers to the value of the product or service of the $i$ sector that will be directly consumed for each additional unit of total output in the production and operation process of the $j$ industry sector, recorded as $a_{i j}$ $(i, j=1,2, \ldots, n)$. The calculation method is 


$$
a_{i j}=\frac{x_{i j}}{X_{j}}, \quad i, j=1,2, \ldots, n .
$$

Among them, $x_{i j}$ is the value of the products or services of the $i$ industrial sector directly consumed during the production and operation of the $j$ industrial sector and $X_{j}$ is the total input of the $j$ sector.

The direct distribution coefficient refers to the amount of value in which the total output of each unit of the $i$ sector is allocated to the $j$ sector for direct use as factors of production, recorded as $h_{i j}(i, j=1,2, \ldots, n)$. The calculation method is

$$
h_{i j}=\frac{x_{i j}}{X_{i}}, \quad i, j=1,2, \ldots, n .
$$

Among them, $x_{i j}$ is the value of the products or services used by the $i$ sector allocated to the $j$ sector and $x_{i}$ is the total output of the $i$ sector.

The above two indicators reflect the direct technical and economic connection between a certain industrial sector and another industrial sector in the process of production and operation from the perspective of input and output, respectively. When the direct consumption coefficient of a certain industry on another industry is larger, it means that the direct dependence of the industry on another industry sector in the production process is more obvious. When the direct distribution coefficient of a certain industry to another industry is larger, it means that the direct support effect of the industry on another industry sector is greater in the production process.

\subsection{Intermediate Demand Rate and Intermediate Input Rate.} The intermediate demand rate refers to the ratio of the intermediate demand for products of the $i$ industrial sector in other sectors of the national economy to the total demand for the products of the industrial sector. It reflects the proportion of the product or service produced by the industrial sector as a means of production and consumption. The calculation method is

$$
w_{i}=\frac{\sum_{j=1}^{n} x_{i j}}{X_{i}}, \quad i=1,2, \ldots, n .
$$

Among them, the numerator is the sum of the intermediate demand for products or services of the $i$ industrial sector by other industrial sectors, and the denominator $X_{i}$ is the total demand for the products or services of the $i$ industrial sector.

Intermediate input rate refers to the ratio of the amount of intermediate input obtained from other industrial sectors during the production and operation of the $j$ industrial sector to its total input, which reflects the proportion of intermediate products obtained by the industrial sector from other industrial sectors in the process of production. The calculation method is

$$
u_{j}=\frac{\sum_{i=1}^{n} x_{i j}}{X_{j}}, \quad j=1,2, \ldots, n,
$$

where the numerator is the sum of the intermediate input of the $j$ industrial sector from other industrial sectors in the production and operation process, and the denominator $X_{j}$ is the total input of the $j$ industrial sector.

The above two characteristic indicators can reflect the overall position of a certain industrial sector in the national economy and its relationship with upstream and downstream industrial sectors. When the intermediate demand rate of a certain industry is higher, it means that the products produced by the industry are more of the nature of the means of production and play the role of the basic industry in the process of correlating with other industries; otherwise, it means that the products produced by the industry are more oriented toward final demand and have a stronger effect on expanding domestic demand. When the intermediate input rate of a certain industry is high, it means that the industry needs to obtain more intermediate products from other industrial sectors in the process of production and operation; that is, the industry sector has a more obvious leading role in its upstream industry; on the contrary, it shows the higher industrial added value of the products of the industry sector.

3.3. The Diffusion Coefficient and Inducing Coefficient. The diffusion coefficient is the ratio of the influence of a certain industrial sector to the average level of the influence of various industrial sectors in the national economy, reflecting the extent to which changes in the final product of the industry affect the production demand of various industrial sectors of the national economy. The calculation method is

$$
F_{j}=\frac{\sum_{i=1}^{n} b_{i j}}{(1 / n) \sum_{j=1}^{n} \sum_{i=1}^{n} b_{i j}}, \quad j=1,2, \ldots, n,
$$

where the numerator is the sum of the $j$ column of the Leontief inverse matrix (Leontief inverse matrix $A$ is the direct consumption coefficient matrix composed of the direct consumption coefficient $a_{i j}$ ), which means that every unit of final product produced by the $j$ industrial sector is the complete demand for products in all sectors of the national economy. The denominator is the average of the column sums of the Leontief inverse matrix.

The inducing coefficient is the ratio of the sensitivity of a certain industry sector to the average level of the sensitivity of each industry sector in the national economy and reflects the degree of demand sensitivity experienced by the industry when the final product of each industry sector in the national economy changes. The formula is as follows:

$$
E_{i}=\frac{\sum_{j=1}^{n} b_{i j}}{(1 / n) \sum_{i=1}^{n}\left(\sum_{j=1}^{n} b_{i j}\right)}, \quad i=1,2, \ldots, n,
$$

where the numerator is the sum of the $i$ row of the Leontief inverse matrix, which represents the total demand for the $i$ industrial sector when each industry sector produces a unit of the final product. The denominator is the average of the row sums of the Leontief inverse matrix. 
The above two coefficients both reflect the role or impact of a certain industrial sector in the national economic system. Among them, the diffusion coefficient represents the degree of impact on the supply sector when the input-output relationship of a certain industrial sector changes. The inducing coefficient indicates the degree to which the inputoutput relationship of a certain industrial sector is affected by the demand sector. The larger the diffusion coefficient, the stronger the demand rate of the industry for other industrial sectors, and the more obvious its pulling function on other industrial sectors. When the inducing coefficient is larger, it means that the relative demand of other industry sectors for the industry is greater; that is, the promoting effect of this industry on other industry sectors will be more obvious.

\section{An Analysis Framework of the Structural Characteristics of China's Entertainment Industry Correlation Network}

In the network analysis stage, the research first converts the direct consumption coefficient matrix obtained from the input-output analysis into a binary adjacency matrix and uses the binary data to construct an industry-correlated network covering China's 149 industrial sectors, so as to fully display the structure of the linkages between the various industrial sectors of the national economy. Then, on this basis, the research will build a self-centered network centered on the typical sectors of the entertainment industry and more specifically show the correlated network structure between the entertainment industry and each directly correlated industry. The calculation methods and descriptions of the characteristic indicators of the industry-correlated networks involved in the research at this stage are as follows.

\subsection{Indicators of the Overall Structural Characteristics of Industrial-Related Networks}

4.1.1. The Structural Characteristics of the Small-World Network. In a network, if most of the nodes in the network are not adjacent to each other, but any node can access other nodes through its adjacent nodes with fewer jumps, then this network will have the characteristics of the small-world structure. The characteristics of the small-world structure are a key index to reflect the network of the overall structure, and they are also the premise to analyze the network structure. Generally, describing mainly the small-world structure characteristics of the network is through two indexes: the average aggregation coefficient and the average shortest path length.

Cluster coefficient is the ratio of the number of connections between adjacent nodes of a node in the network to the number of possible connections, which reflects the degree of the close connection between a node in the network and its neighbors. And the average agglomeration coefficient is the average of the agglomeration coefficient of each node in the network, reflecting the degree of agglomeration of the whole network. In industrial related networks, the higher the agglomeration coefficient is, the closer the technological and economic connection between each industrial node in the network and its neighboring nodes is. The calculation formula of the average clustering coefficient in the directed network is as follows:

$$
\bar{C}=\frac{1}{n} \sum_{i=1}^{n} \frac{A_{i}}{k_{i}\left(k_{i}-1\right)} .
$$

Among them, the numerator $A_{i}$ is the number of edges that actually exist between neighboring nodes of node $v_{i}$ and the denominator is the maximum number of edges that may exist between neighboring nodes of node $v_{i}$.

The shortest path length is the distance of the shortest path among the multiple paths connected between two nodes, while the average shortest path is the average of the shortest distance between any two points in the network. In industrial related networks, the average shortest path length reflects the transmission efficiency of resources and information among various industrial departments. The smaller the average shortest path length is, the closer the relationship between various industries in the network is, and the more efficient the circulation of resources and information among industrial departments is. The calculation method is

$$
d=\frac{1}{N(N-1)} \sum_{i, j \in N, i \neq j} d_{i j} .
$$

Among them, $d_{i j}$ is the shortest path length between nodes $v_{i}$ and $v_{j}$ and $N$ is the number of nodes in the network.

In network analysis, if a network has both a higher average agglomeration coefficient and a lower average shortest path length, it indicates that the network has the structural characteristics of a small-world network [11]. For the industrial related networks, the more obvious the smallworld feature is, the closer the connection between each industrial sector and its neighboring industrial sector is, and the higher the quality and efficiency of the industrial sector in the exchange of resources or information are.

4.1.2. Network Density. Network density refers to the ratio between the actual number of existing edges and the maximum number of possible existing edges among all nodes in a certain network. It reflects the tightness of connections among all nodes in the network from the overall level. The calculation method of network density in a directed network is as follows:

$$
\Delta=\frac{L}{N(N-1)} .
$$

Among them, $L$ is the number of edges that actually exist in the network and $N$ is the number of nodes in the network.

In the industrial related network, the level of network density reflects the close degree of economic interaction between various industrial departments and also reflects the close degree of connection among the members of the entire industrial related network, which is an important indicator to understand its structure. 


\subsection{Industrial Node Characteristic Indexes of Industrial- Related Network}

4.2.1. Node Degree. Node degree is the number of edges connected between a node and other nodes in the network. In a directed network, node degree is divided into point-out degree and point-in degree according to edge pointing, in which point-out degree refers to the number of edges where the node points to other nodes, while point-in degree refers to the number of edges where other nodes point to the node.

On the whole, node degree in the industrial related network reflects the position of a particular industrial department in the overall industrial association network. The higher the node degree of an industrial department, the more other industrial departments it is associated with, and the greater its influence in the industrial related network. As the industrial related network constructed by direct consumption coefficient has directivity, the node degree in the industrial association network is also divided into point-in degree and point-out degree. The point-in degree indicates how many final products of the industrial sector need to be consumed in the production process, reflecting the forward relevance of the industrial sector, and the point-out degree indicates how many production demands of industrial sectors will be met by the final products of the industry sector, reflecting the backward correlation of the industry sector.

4.2.2. Betweenness Centrality. In the industry-related network, betweenness centrality refers to the number of times where a node in a network acts as the shortest path bridge between other two nodes, reflecting the intermediary role and importance of this node in the network. The higher intermediate centrality is, the more obvious the industrial sector is as an intermediary to connect other industrial sectors, and the more it is at the center of the industrial related network. The calculation method is as follows:

$$
C_{B}\left(v_{i}\right)=\sum_{j<k} \frac{g_{j k}\left(v_{i}\right)}{g_{j k}} .
$$

Among them, $g_{j k}$ represents the number of shortest paths between node $v_{j}$ and $v_{k}$ and $g_{j k}\left(v_{i}\right)$ represents the number of shortest paths between node $v_{j}$ and $v_{k}$ that pass through node $v_{i}$.

4.3. Data Sources, Industrial Sector Selection, and Data Processing Methods. In this study, the original data were used as "China's 2017 Input-Output Table" released by the National Bureau of Statistics of China in 2019. Different from the classifying way in previous years of 42 industrial categories, this input-output table divides the production sectors of China's national economy into 149 specific industrial sectors. According to the classification interpretation of each industrial sector, among all industrial sectors, the "entertainment" sector includes indoor entertainment activities, amusement parks, leisure and sightseeing activities, lottery activities, cultural and sports entertainment activities, and other entertainment industries. "Radio, television, film, and film recording production" departments include radio, television, film, and television program production, integrated broadcasting control of radio and television, film, and radio and television program distribution, film screening, recording production, and other industries [12]. The above two industrial sectors basically cover the core industries of China's entertainment industry. Therefore, this study will select "entertainment" and "radio, television, film, and film recording production" as the representatives of the entertainment industry to conduct research and analysis.

In data processing, Excel and RStudio were first used to conduct input-output analysis on the original data to calculate the industrial related characteristic indexes of the above two industrial sectors. Then, Gephi and the direct consumption coefficient matrix obtained from the previous analysis were used to construct the overall industrial association network and the entertainment industry direct association network. Furthermore, this paper analyzes the structural characteristics of the association network of the core departments of the entertainment industry.

\section{Input-Output Analysis of the Related Characteristics in China's Entertainment Industry}

5.1. Direct Consumption Coefficient and Direct Distribution Coefficient of the Entertainment Industry. According to equations (1) and (2), the direct consumption coefficient and direct distribution coefficient of entertainment, radio, television, film, and film recording production are measured by using the basic flow table in the input-output table.

According to the calculation results of the direct consumption coefficient, "entertainment" and "radio, television, film, and video recording production" will have a direct consumption relationship with other 111 and 99 industrial sectors, respectively, in the production process. It shows that the core sector of China's entertainment industry will produce direct demand for most other industrial sectors in the production process and has a wide range of pulling capacity for the development of upstream industries. After ranking, the 10 industrial sectors that are most closely related to the direct consumption of the entertainment industry are shown in Table 1.

From the above statistical results, it can be seen that the three industry sectors with the highest direct consumption coefficients, which represent the indoor exterior entertainment industry, are the real estate, beverage, and alcohol and liquor industries. The entertainment industry sector's direct consumption coefficients for the above three industry sectors all exceed 0.04 . It shows that every 10,000 yuan of indoor and outdoor leisure and entertainment products produced by the entertainment industry directly consume more than 400 yuan of the products of these sectors, and the direct dependence and traction effect on them is the largest compared with other industrial sectors. Representing the film and television entertainment industry, the radio, television, film, and video recording production industries have 
TABLe 1: Statistical table of direct consumption coefficient of the Chinese entertainment industry on other industrial sectors.

\begin{tabular}{lccc}
\hline Entertainment & $\begin{array}{c}\text { Direct consumption } \\
\text { factor }\end{array}$ & \multicolumn{2}{c}{ Radio, film, television, and (other) audiovisual media } \\
Industry sector & 0.0611 & Manufacture of textiles, clothing; apparel industry & Direct consumption factor \\
\hline $\begin{array}{l}\text { Real estate } \\
\text { Beverages }\end{array}$ & 0.0497 & Commercial services & 0.0602 \\
$\begin{array}{l}\text { Manufacture of alcohol } \\
\text { Money, finance, and other }\end{array}$ & 0.0433 & Catering & 0.0598 \\
financial services & 0.0367 & Radio, film, television, and (other) audiovisual media & 0.0427 \\
Commercial services & 0.0277 & Accommodation & 0.0403 \\
Entertainment & 0.0270 & Special chemical products and & 0.0259 \\
Manufacture of tobacco & 0.0204 & explosives, pyrotechnics, fireworks products & 0.0255 \\
Retail trade & 0.0191 & Other services & 0.0156 \\
Refined tea & 0.0141 & Aerospace & 0.0154 \\
Wholesale trade & 0.0138 & Real estate & 0.0140 \\
\hline
\end{tabular}

the highest direct consumption coefficients in three industrial sectors: textile, clothing, business services, and catering industries. Among them, the direct consumption coefficient of the broadcasting, television, film, and film and television recording production industries on the textile, clothing, and business services is the same, which is about 0.06 . It shows that for every 10,000 yuan of film and television entertainment products produced by the radio, television, film, and film and television recording production industries, the direct consumption of these two departments' products is about 600 yuan, which has a strong backward correlation.

Comparing the 10 industry sectors with the highest direct consumption coefficients of the two typical industry sectors in China's entertainment industry, we can find that the only industries in the top ten of the two typical industry sectors in the entertainment industry are real estate and business services. This shows that China's entertainment industry covers a wide range of backward correlations, and it has a certain degree of dependence on most other industries and will also have a certain driving effect on its development.

From the calculation results of the direct distribution coefficient, it can be seen that there is more or less a direct distribution relationship between the entertainment industry and the radio, television, film, and film recording production industry and all other industrial sectors. After ranking, the 10 industrial sectors with the highest direct distribution coefficients of the two industrial sectors are shown in Table 2.

From the above statistical results, although there is a certain direct distribution relationship between the two typical Chinese entertainment industries and other industries, it can be seen from the numerical point of view that the direct distribution coefficient is the highest industry itself, and of the other sectors under the ranking position with direct distribution coefficient significantly less than the direct consumption coefficients, it is shown that, in addition to the final demand oriented, the products or services produced by China's entertainment industry are mainly to meet the needs of its own industry, and it is difficult to promote the development of other industrial sectors through direct supply.

\subsection{Intermediate Demand Rate and Intermediate Input Rate of} the Entertainment Industry. According to equations (3) and (4), the research has measured the intermediate demand rate and intermediate input rate of two typical industrial sectors in China's entertainment industry. The results are shown in Table 3.

It can be seen from Table 3 that the intermediate demand rates of the entertainment industry sector representing the indoor exterior light entertainment industry and the broadcasting, television, film, and film and television recording production sector representing the film and television entertainment industry are $55.40 \%$ and $37.51 \%$, respectively, in 149 industries across the country. The rankings in the departments are relatively low. From the perspective of the intermediate investment rate, the value and ranking of the two typical sectors of China's entertainment industry are basically the same, with an intermediate investment rate lower than $50 \%$, ranking basically at the bottom of all industrial sectors in China.

A comprehensive comparison of the intermediate demand rate and intermediate input rate of the two industrial sectors shows that although the intermediate demand rate of the entertainment industry, which represents the indoor exterior light entertainment industry, is slightly higher than $50 \%$, it is still relatively low in terms of ranking. Therefore, the two typical sectors of the entertainment industry both show the characteristics of low intermediate demand and low intermediate input. According to the industry classification method of input-output analysis, this means that China's entertainment industry as a whole shows the characteristics of the basic industry of final demand, and the products and services it produces are more directly meeting final demand, which is positive for expanding consumption. Because of the low intermediate input rate, the industry has a high industrial added value, which can create economic value and stimulate economic growth. 
TAвLE 2: Statistical table of direct distribution coefficients of the Chinese entertainment industry to other industrial sectors.

\begin{tabular}{|c|c|c|c|}
\hline Entertainment & & Radio, film, television, and (other) & audiovisual media \\
\hline Industry sector & $\begin{array}{l}\text { Direct consumption } \\
\text { factor }\end{array}$ & Industry sector & Direct consumption factor \\
\hline Entertainment & 0.0270 & $\begin{array}{l}\text { Radio, film, television, and (other) } \\
\text { audiovisual media }\end{array}$ & 0.0403 \\
\hline Insurance & 0.0121 & $\begin{array}{c}\text { Radio, television, and satellite transmission } \\
\text { services }\end{array}$ & 0.0206 \\
\hline $\begin{array}{l}\text { Monetary and financial services and } \\
\text { other financial activities }\end{array}$ & 0.0111 & Water transport & 0.0070 \\
\hline Culture and arts & 0.0066 & $\begin{array}{c}\text { Radio and television equipment and radar } \\
\text { and ancillary equipment }\end{array}$ & 0.0060 \\
\hline Sports & 0.0061 & Entertainment & 0.0055 \\
\hline Resident services & 0.0038 & Accommodation & 0.0032 \\
\hline Internet and related services & 0.0032 & Production and distribution of tap & 0.0026 \\
\hline $\begin{array}{l}\text { Loading/unloading, removal, and } \\
\text { storage }\end{array}$ & 0.0031 & Sports & 0.0023 \\
\hline $\begin{array}{l}\text { Radio, television, and satellite } \\
\text { transmission services }\end{array}$ & 0.0029 & Social work & 0.0020 \\
\hline Entertainment & 0.0270 & Other electrical machinery and equipment & 0.0020 \\
\hline
\end{tabular}

TABLe 3: Statistical table of intermediate demand rate and intermediate investment rate of the Chinese entertainment industry.

\begin{tabular}{|c|c|c|c|c|}
\hline Industry sector & Intermediate demand rate & Rank & Intermediate investment rate & Rank \\
\hline Entertainment & 0.5540 & 97 & 0.4455 & 130 \\
\hline Radio, film, television, and (other) audiovisual media & 0.3751 & 116 & 0.4571 & 129 \\
\hline
\end{tabular}

\subsection{The Diffusion Coefficient and Inducing Coefficient of the} Entertainment Industry. According to equations (5) and (6), the diffusion coefficient and inducing coefficient of two typical industry sectors in China's entertainment industry are further measured by using the calculated direct consumption coefficient. The results are shown in Table 4.

From the diffusion coefficient calculated result on behalf of the film and television entertainment industry of radio, television, film, and video recording production sector, the diffusion coefficient is slightly higher than the representative of the indoor and outdoor sightseeing leisure entertainment industry sector in the entertainment business, but it is obviously lower than the average level of other industries in China, among all sectors. From the calculation results of the reaction coefficient, the entertainment industry sector and radio, television, film, and film recording production industry sector of the reaction coefficient are basically the same but are lower than the national average level.

A comprehensive comparison of the diffusion coefficient and the inducing coefficient of two typical industry sectors in China's entertainment industry shows that the diffusion coefficient of both is higher than the inducing coefficient. This indicates that the above industries play a more obvious role as users in China's national economy, and their demand for other industrial sectors is higher than that of other industrial sectors in the process of production and operation, so their pulling effect is more obvious; that is, their backward correlation with other industrial sectors is more close. However, from the numerical point of view, the diffusion coefficient of these two industrial sectors is higher than the inducing coefficient, but compared with other industrial sectors in the country, their influence level is relatively low, and their economic driving effect is still limited.

\section{Analysis on the Characteristics of Industrial- Related Network Structure of the Chinese Entertainment Industry}

Through the input-output analysis of the industrial relevance characteristics of China's entertainment industry, the research has sorted out the general industrial relevance of China's entertainment industry. At this stage, the research will build a more systematic description of the entertainment industry's industry-related network structure characteristics by constructing an industry-related network based on the data obtained from the input-output analysis.

6.1. Construction of Industrial-Related Network. According to research needs, this research will first build the overall industry-related network of China's industry sectors based on the direct consumption coefficients obtained from the previous research, and then on this basis, we will build China's entertainment industry with two typical industry sectors as the center connected directly to the network.

The industrial relational network constructed by this research is an unauthorized directed network, and the direction of the edges is the direction of economic and technological connections between various industrial departments. Whether there is a connection between various industrial departments requires the binary value obtained by the direct consumption coefficient matrix conversion adjacency matrix for judgment. In order to show the network structure more clearly, it is necessary to select an appropriate threshold to filter the weak connections between nodes in the network. Referring to the practice of Wang [13], Li [10], and others, this study selected the mean value of direct 
TABLE 4: Statistics of diffusion coefficient and inducing coefficient of the Chinese entertainment industry.

\begin{tabular}{|c|c|c|c|c|}
\hline Industry sector & Diffusion coefficient & Rank & Inducing coefficient & Rank \\
\hline Entertainment & 0.7275 & 133 & 0.4881 & 109 \\
\hline Radio, film, television, and (other) audiovisual media & 0.7857 & 126 & 0.4612 & 123 \\
\hline
\end{tabular}

consumption coefficient matrix 0.004454 as the threshold value. If the direct consumption coefficient of the industrial sector $I$ to industrial sector $j$ is greater than the threshold value, the corresponding adjacency matrix is 1 . This indicates that there is an edge pointing to $I$ from $j$ between industrial sector $i$ and industrial sector $j$. In addition, since the research mainly wants to show the correlation between the $X$ industry and other industries, the self-loop of industrial nodes is removed during the network construction [14]. The overall industrial related network constructed according to this matrix is shown in Figure 1 (because there are too many nodes, the industrial node names are not marked in the figure).

In the graph of the overall industry association network, the research selects entertainment, radio, television, film, and film and television recording production as the center, determines the depth of 1, filters the overall association network, and constructs the corresponding Chinese entertainment industry direct association network. The resulting network diagram is shown in Figures 2 and 3.

6.2. Analysis of the Overall Structural Characteristics of the Entertainment Industry-Related Network. According to equations (7)-(9), the average agglomeration coefficient, average shortest path length, and network density of the above three industrial association networks are, respectively, measured, and the basic information of the three network graphs is statistically analyzed. The results are shown in Table 5.

First of all, from the perspective of the basic information of the overall industrial related network, 149 industrial departments in China are all covered in the overall industrial association network, and the number of directed edges between industrial nodes is 2933, indicating that all industrial departments in China will still be related to other industrial departments through direct or indirect connections after filtering out weak connections. And in the direct industrial related network centered on two typical Chinese entertainment industry sectors, although the broadcast, television, film, and video recording industry is a directly close network within the industry sector nodes and directed edge quantity is higher than that of the entertainment industry department, compared with the overall industry association network, the number of industry sectors in these two direct industry association networks is relatively small. This shows that although China's entertainment industry has experienced a period of rapid development, the industrial sectors that have a strong direct connection with China's entertainment industry still account for a small proportion in all industrial sectors.

Secondly, from the perspective of the average agglomeration coefficient, the average agglomeration coefficients of

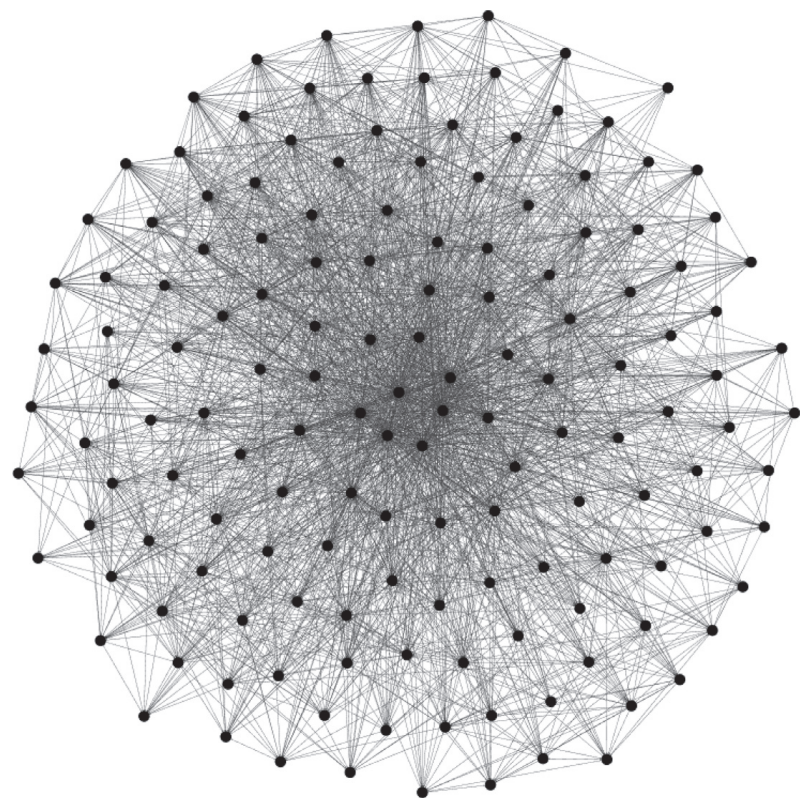

FIgURE 1: China's overall industrial related network.

China's overall industrial association network and the network directly associated with typical industrial sectors of China's entertainment industry are $0.34,0.51$, and 0.50 , respectively. On the whole, the average agglomeration coefficient of these three networks is relatively high, indicating that, in the above association network, the association between industrial nodes and their neighboring industries is relatively close. Compared to the overall industry-related network, two direct industrial networks can be found where the Chinese entertainment industry departments of the two typical industries directly affiliate network average concentration coefficient, the related network was greater than the overall industry, and the entertainment industry of China is directly related to individual industry between nodes in the network economy as a whole technical contact more closely.

Thirdly, from the perspective of average shortest path length, the average shortest path length of the three industrial related networks is relatively close, and all of them are relatively short, indicating that no matter the overall network or the direct network, any industrial nodes in the network can generate contact through a shorter path, and the overall circulation speed and efficiency of resources are relatively high. Combined with the average agglomeration coefficient of the three networks, the three industrial related networks constructed in this study all have high average agglomeration coefficient and short average shortest path length, indicating that the above networks all have the structural characteristics of small-world networks. 


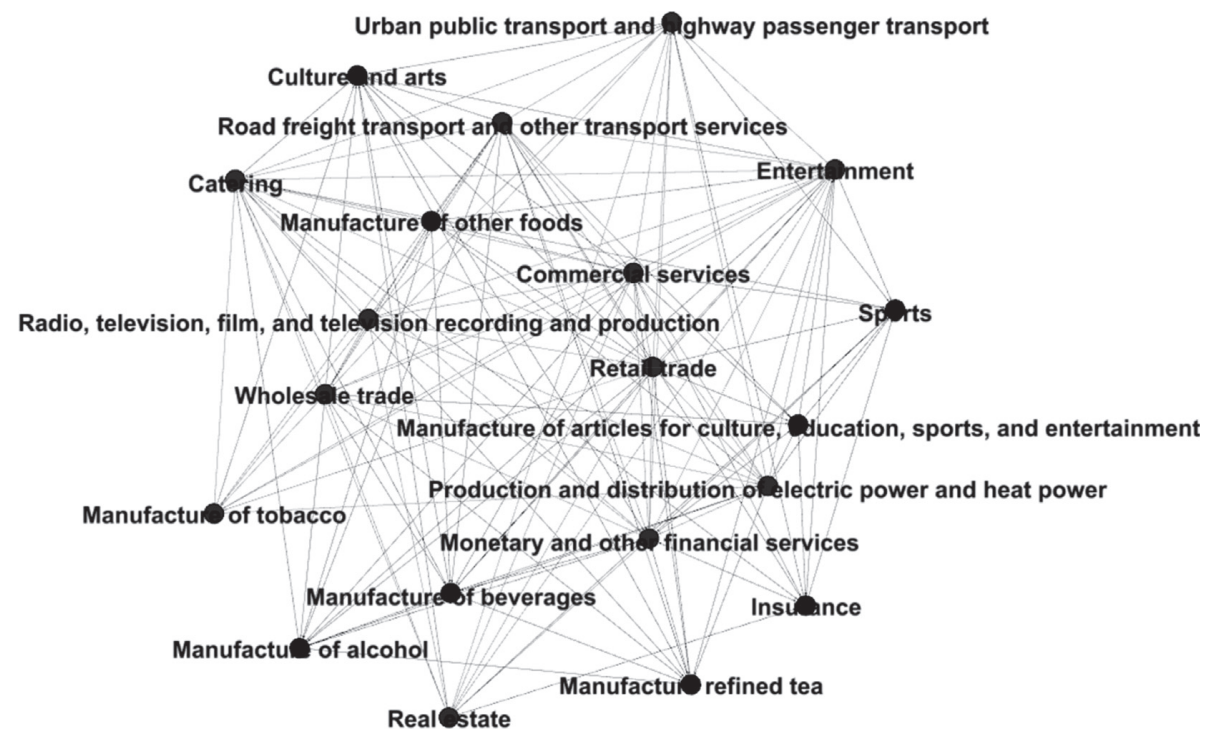

FIgURE 2: Diagram of the direct industrial related network of the entertainment industry.

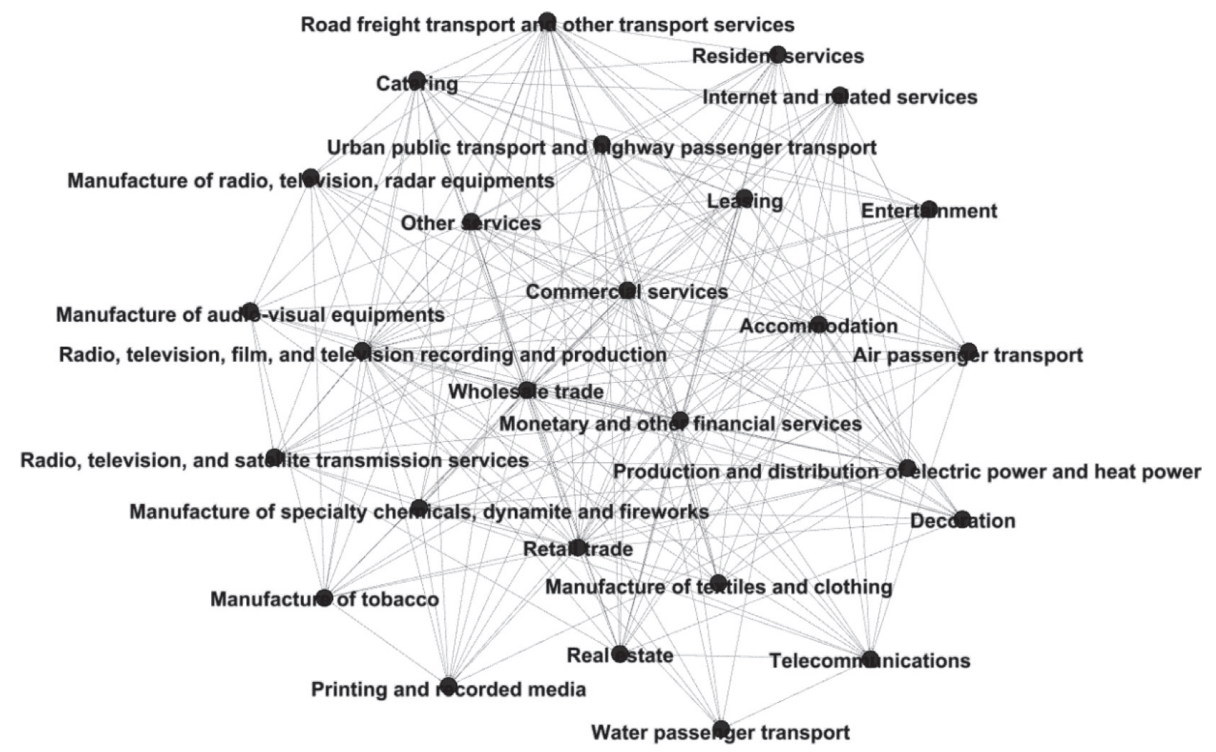

FIGURE 3: Diagram of direct industry connected network of broadcasting, television, film, and video recording production industry.

TABLE 5: Statistical table of the overall structural characteristics of the industrial related network.

\begin{tabular}{|c|c|c|c|c|c|}
\hline Network type & $\begin{array}{c}\text { Node } \\
\text { number }\end{array}$ & Edges & $\begin{array}{l}\text { Average agglomeration } \\
\text { coefficient }\end{array}$ & $\begin{array}{l}\text { Average shortest path } \\
\text { length }\end{array}$ & Network density \\
\hline The whole industry-related network & 149 & 2933 & 0.34 & 2.20 & 0.13 \\
\hline $\begin{array}{l}\text { The entertainment industry is directly connected } \\
\text { to the Internet }\end{array}$ & 20 & 158 & 0.51 & 1.70 & 0.42 \\
\hline $\begin{array}{l}\text { The radio, television, film, and video recording } \\
\text { industries are directly connected }\end{array}$ & 27 & 261 & 0.50 & 1.70 & 0.37 \\
\hline
\end{tabular}

Finally, from the perspective of network density, among the three industrial related networks, China's overall industrial related network has the lowest network density, which is 0.13 . The network densities of the other two direct industrial related networks were close, 0.42 and 0.37 , respectively, which were significantly higher than the overall industrial related network. It can be seen from this that, within the direct industrial related network of China's core industry sectors, strong economic interaction has been established among various industrial sectors, and there is a 
TABLE 6: Statistical table of node characteristics of the entertainment industry.

\begin{tabular}{|c|c|c|c|c|c|c|c|c|}
\hline \multirow[t]{2}{*}{ Industry nodes } & \multicolumn{2}{|c|}{ Node degree } & \multicolumn{2}{|c|}{ Point-in degree } & \multicolumn{2}{|c|}{$\begin{array}{l}\text { Point-out } \\
\text { degree }\end{array}$} & \multicolumn{2}{|c|}{$\begin{array}{c}\text { Betweenness } \\
\text { centrality }\end{array}$} \\
\hline & Value & Rank & Value & Rank & Value & Rank & Value & Rank \\
\hline Entertainment & 20 & 126 & 16 & 97 & 4 & 109 & 283.08 & 18 \\
\hline Radio, film, television, and (other) audiovisual media & 26 & 101 & 22 & 61 & 4 & 109 & 36.71 & 98 \\
\hline
\end{tabular}

high synergistic effect among various industrial sectors. Its industrial related channels and cooperative behaviors are higher than the overall level of China's industrial related network.

Through the above analysis, it can be found that the directly related networks related to China's entertainment industry generally have the characteristics of high agglomeration coefficient, short average path, and high network density, but few nodes. This feature indicates that although the number of industrial sectors with a strong correlation with China's entertainment industry is obviously rare, the established industrial sectors have frequent interactions and close relationships within the directly related network [15]. Although such network structures will expand the driving ability of each other in the same direction by forming a small industrial group, its influence will be limited by the number of nodes, and it is difficult to drive the common development of most industries.

6.3. Analysis of Node Characteristics of the Entertainment Industry's Related Network. After sorting the overall characteristics of the industry-related network, we study further using Gephi software and put two typical Chinese entertainment industry sectors in China's overall industrial connection within the network. And the node characteristics were more specific; thus, there is a more comprehensive display of the entertainment industry in the positioning and characteristics of the industrial structure of China. The measurement results of network node characteristics of specific industrial sectors are shown in Table 6.

First of all, from the point of view of the node degree of industrial nodes. The nodal degrees of the entertainment industry, which represents the indoor and outdoor tourism and leisure and entertainment industry, and the radio, television, film, and film recording production industry, which represents the film and television entertainment industry, are 20 and 26, respectively, ranking the lowest among all industrial sectors in China. It can be seen from this that China's entertainment industry is still in a marginal position in the national overall industrial network, and the number of industrial sectors with a strong correlation with it is still relatively small.

Secondly, the specific point-in degree and point-out degree are analyzed. The point-in degree and point-out degree of the entertainment industry, which represents the indoor and outdoor sightseeing and leisure and entertainment industry, rank relatively low among all the industry sectors. This indicates that the forward and backward radiating driving ability of the industrial sector is relatively limited after filtering out the weak connection, but in comparison, the backward correlation is higher than the forward correlation in the industrial related network. However, in the radio, television, film, and film and television recording production industry, which represents the film and television entertainment industry, the point-in degree is 22, ranking relatively higher among 149 industrial sectors in China. This shows that the industrial sector is supported a lot by other industrial sectors in the production process, and it will have a certain radiating and driving effect on the upstream industry during its development.

Finally, from the calculation results of the betweenness centrality of two industrial sector nodes. The betweenness centrality of the entertainment industry and the broadcasting, television, film, and film recording production industry are, respectively, 283.08 and 36.71, which have a great difference in the rank among all Chinese industrial sectors. This indicates that different industrial sectors in China's entertainment industry have different roles in China's national industrial structure. Though the entertainment industry sector, representing indoor and outdoor tourism and leisure and entertainment industry, has a less strong correlation in the industrial related network, it plays a relatively obvious intermediary role in the overall related network. Compared with other industrial sectors, the ability of resource control and regulation is more prominent, and it has a special position in the overall industrial related network.

\section{Conclusion}

In order to better clarify the characteristics of economic links between China's entertainment industry and other industrial sectors and further clarify the role of the entertainment industry in China's industrial development and its positioning in China's overall industrial related network, this study is based on the dual perspectives: input-output analysis and network analysis. Taking the typical industry sectors of the Chinese entertainment industry-entertainment industry sector and radio, television, film, and film recording production industry sector-as representatives, this paper systematically and quantitatively studies the characteristics of the industrial related and industrial related network structure of Chinese entertainment industry. Through the two-stage research, the following conclusions are drawn.

Firstly, through the characteristics of the Chinese entertainment industry-related network of input-output analysis, the study found that the Chinese entertainment industry as a whole showed the characteristics of the final demand basic industries, in the process of production in the industry, for most other sectors have certain dependence, 
and its products and services more directly meet the final demand. This characteristic shows that the development of China's entertainment industry plays a positive role in expanding consumption to a certain extent. Moreover, due to the low intermediate investment rate, the industry has a high added value, which can better create economic value and drive economic growth. It can be seen that, in order to play the role of China's entertainment industry in expanding consumption, it needs the development of other related industries as a foundation. Therefore, in the current economic development environment of China, in addition to the acceleration of the entertainment industry itself, the development of other related industries also needs to be promoted simultaneously.

Secondly, through the analysis of the overall structural characteristics of China's overall industrial association network and China's entertainment industry's direct industrial association network, the research finds that the direct association network related to China's entertainment industry generally has the characteristics of a high agglomeration coefficient, short average path, and high network density, but few nodes. This characteristic indicates that although the number of industrial sectors with strong correlation with China's entertainment industry is obviously rare, the established industrial sectors have frequent interaction and close relationships within the direct correlation network. Although such network structures will expand the driving ability of each other in the same direction by forming a small industrial group, its influence will be limited by the number of nodes, and it is difficult to drive the common development of most industries. Therefore, the research believes that it is necessary to further expand the downstream industrial chain related to the entertainment industry and expand the overall scale of the direct industrial association network of the entertainment industry. This will extend its original industry-driven capacity to more industries.

Third, through the analysis of the overall industry-related network in China to Chinese entertainment typical industry departments within the network node characteristics, the study found that the backward correlation of typical industry sectors of Chinese entertainment is obviously higher than the forward correlation. This shows that in the development process of the Chinese entertainment industry, there will be a certain amount of radiation on the upstream industry. In addition, although Chinese entertainment industry has few strong correlations within the industrial connection network, its core industrial sector has a clear intermediary role in the overall connection network. This shows that Chinese entertainment industry's resource control and adjustment capacity are more prominent than other industrial sectors.

\section{Data Availability}

The original data used in this study are from the inputoutput tables of China released by the National Bureau of Statistics of China in 2019. The original data used to support the findings of this study are available from http://www.stats. gov.cn/ztjc/tjzdgg/trccxh/zlxz/trccb/201701/ t20170113_1453448.html.

\section{Conflicts of Interest}

The authors declare that they have no conflicts of interest.

\section{Acknowledgments}

This work was supported in part by the Social Sciences Foundation of Shaanxi Province, China (Grant no. 2019R007).

\section{References}

[1] J. He, "Study on development orientation of urban leisure industry and its products--based on an analysis of leisure demand structure and behaviors," Tourism Tribune, vol. 23, no. 7, pp. 13-17, 2008.

[2] J. Xia and Y. Xiao, "Development trend and future orientation of digital entertainment consumption," Reform, vol. 32, no. 12, pp. 56-64, 2019.

[3] C. Tao, M. Xu, and J. Yu, "Government innovation investment, inter-regional correlation and industrial structure upgrading: an empirical analysis of 283 cities in China," Statistics and Information Forum, vol. 35, no. 7, pp. 89-100, 2020.

[4] Q. Qing and Y. Hu, "Leisure industry: review of the related in China," Economist, vol. 18, no. 4, pp. 40-46, 2006.

[5] F. Xiong, X. Wang, S. Pan, H. Yang, H. Wang, and C. Zhang, "Social recommendation with evolutionary opinion dynamics," IEEE Transactions on Systems, Man, and Cybernetics: Systems, vol. 50, no. 10, pp. 3804-3816, 2020.

[6] Q. Zhao and Q. Yan, "Research on the structural characteristics of China's industrial correlation network," Statistics and Decision, vol. 32, no. 15, pp. 104-108, 2017.

[7] L. Jing, C. Shu, G. Wan, and C. Fu, "Study on the spatial correlation and explanation of regional economic growth in China-_based on analytic network process," Economic Research Journal, vol. 49, no. 11, pp. 4-16, 2014.

[8] H. Qian, X. Yang, J. Ding, and L. Yang, "Whole social network for professional athletes in China," Journal of Wuhan Institute of Physical Education, vol. 50, no. 7, pp. 77-83+88, 2016.

[9] Z. Wang, S. Liu, W. Wei, and Y. Yao, "Spatial characteristics of China's local government debt risk correlation network and the influencing factors," Statistics and Information Forum, vol. 34, no. 12, pp. 22-31, 2019.

[10] Y. Hu, F. Xiong, S. Pan, X. Xiong, L. Wang, and H. Chen, "Bayesian personalized ranking based on multiple-layer neighborhoods," Information Sciences, vol. 542, pp. 156-176, 2021.

[11] F. Wasserman, Social Network Analysis: Methods and Applications, China Renmin University Press, Beijing, China, 2011.

[12] National Economic Accounting Department, National Bureau of Statistics, Input-Output Tables of China, China Statistics Press, Beijing, China, 2019.

[13] T. Wang, "Research on the general feature of Chinese industrial structure based on social network analysis," Science Research Management, vol. 35, no. 7, pp. 124-129, 2014.

[14] D. Zhai and J. Han, "IUR knowledge collaboration research based on networked evolutionary game," Statistics and Information Forum, vol. 34, no. 2, pp. 64-70, 2019.

[15] F. Xiong, W. Shen, H. Chen, S. Pan, X. Wang, and Z. Yan, "Exploiting implicit influence from information propagation for social recommendation," IEEE Transactions on Cybernetics, vol. 50, no. 10, pp. 4186-4199, 2020. 